\title{
Acute cardiac injury is associated with adverse outcomes, including mortality in COVID-19 patients
}

\author{
A single-center experience
}

Kashif B. Naeem, MBBS, MRCP, Mahmood Y. Hachim, MBBS, PhD, Ibrahim Y. Hachim, MBBS, PhD, Ayman Chkhis, MSc, Rajesh Quadros, MBBS, Haifa Hannawi, BDS, PhD, Issa Al Salmi, MBBS, PhD, Fahdah Alokaily, MBBS, PhD,

Suad Hannawi, FRCP, PhD.

\begin{abstract}

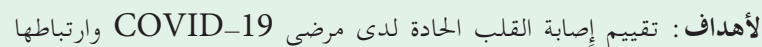

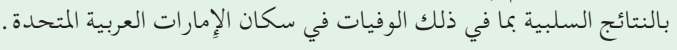

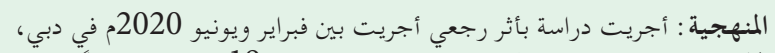

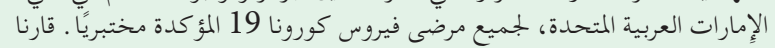

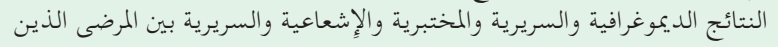
يعانون من إِصابة قلبية حادة وغير مصابين.

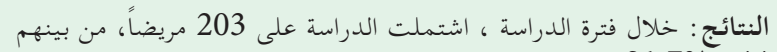
44

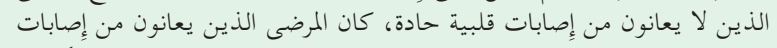

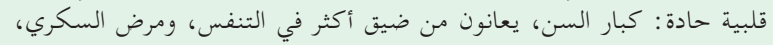

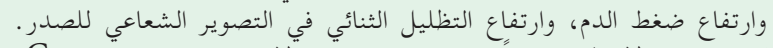

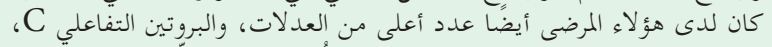

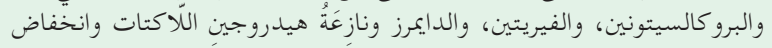

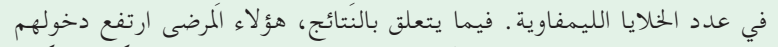

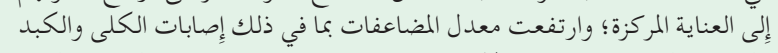

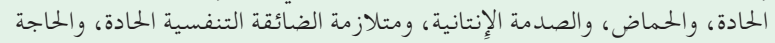

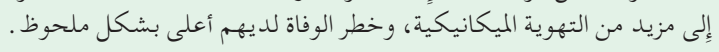

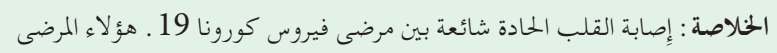

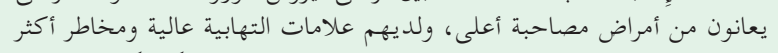

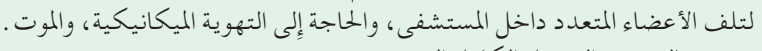

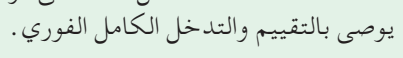

Objectives: To evaluate acute cardiac injury in COVID-19 patients and its association with adverse outcomes including mortality in the United Arab Emirates (UAE) population.

Methods: A retrospective study conducted between February and June 2020 in Dubai, UAE, for all laboratory-confirmed Coronavirus disease-19 patients. Demographic, clinical, laboratory, radiological, and clinical outcomes were compared between patients with and without acute cardiac injury.

Results: During the study period, 203 patients were included, of which, $44(21.7 \%)$ had evidence of acute cardiac injury. Compared with patients without acute cardiac injury, patients with acute cardiac injury were: older, had more shortness of breath, diabetes, hypertension, and more bilateral airspace shadowing on admission chest radiography. These patients also had a higher neutrophil count, C-reactive protein, procalcitonin, ferritin, D-dimers and lactate dehydrogenase but lower lymphocyte count. Regarding outcomes, these patients had higher intensive care admissions; a higher rate of complications including acute kidney and liver injury, acidosis, septic shock, acute respiratory distress syndrome, needed more mechanical ventilation, and had a significantly higher risk of death.

Conclusion: Acute cardiac injury is common among Coronavirus disease-19 patients. These patients present with higher comorbidities, have high inflammatory markers and have greater risk for in-hospital multiorgan damage, need for mechanical ventilation, and death. Prompt full assessment and intervention are recommended.

Keywords: cardiac injury, Corona virus, COVID-19, acute respiratory distress syndrome, mortality

Saudi Med J 2020; Vol. 41 (11): 1204-1210 doi: $10.15537 /$ smj.2020.11.25466

From the Ministry of Health and Prevention (Naeem, Chkhis, Quadros, Hannawi H, Hannawi S); College of Medicine (Hachim M), Mohammed bin Rashid University of Medicine and Health Sciences, Dubai; from the Clinical Sciences Department (Hachim I), College of Medicine, University of Sharjah, Sharjah, United Arab Emirates; from The Royal Hospital (Hannawi H, Al Salmi), Muscat, Oman; and from the Department of Rheumatology (Alokaily), Prince Sultan Riyadh Military Medical City, Riyadh, Kingdom of Saudi Arabia.

Received 12th August 2020. Accepted 6th October 2020.

Address correspondence and reprint request to: Dr. Suad Hannawi, Ministry of Health and Prevention, Dubai, United Arab Emirates. E-mail: suad1@ausdoctors.net

ORCID ID: https://orcid.org/0000-0002-5689-6710 
C orona virus disease-2019 (COVID-19), caused by Severe Acute Respiratory Syndrome Coronavirus 2 (SARS-CoV-2), resulted in the COVID-19 pandemic and healthcare challenge to almost all countries in the world. Corona virus disease-2019 was first reported in Wuhan, China in December 2019. ${ }^{1}$ As of June 29, 2020 , the total number of confirmed cases worldwide were 10,199,798, with 502,946 confirmed deaths, whereas, United Arab Emirates (UAE) had 47,797 confirmed cases with 313 deaths. $^{2}$

Although respiratory failure has been the major concern in Covid-19 infection, cardiac injury manifested by a rise in high-sensitivity troponin has gained considerable attention due to its reported association with mortality. 3,4 Subsequently, the American College of Cardiology clinical bulletin released in February 2020 has highlighted the incidence of acute onset heart failure, myocardial infarction, myocarditis and cardiac arrest in Covid-19 as higher cardiometabolic demand in acute illness can precipitate cardiac complications. ${ }^{5}$ Although the exact pathophysiology remains unclear, several mechanisms have been proposed. Cytokine release syndrome ${ }^{6}$ with high levels of interleukin-6, interferon-gamma, interferon-inducible protein-10, and monocyte chemoattractant protein-1, angiotensinconverting enzyme 2-related signaling pathways, and intractable hypoxemia due to acute respiratory distress syndrome have all been suggested. ${ }^{7}$

Data is scarce from the Middle East region in this regard. Hence, we conducted this study in confirmed Covid-19 patients admitted to main Ministry of Health Hospital in Dubai, UAE and compared the clinical characteristics, laboratory parameters, and clinical outcomes in patients with- and without cardiac injury.

Methods. This study was conducted at Al Kuwait Hospital, Dubai, UAE, between February 21, 2020, and June 24, 2020. We only included patients who were admitted to the hospital after a positive COVID-19 RNA polymerase chain reaction (PCR) test. The Sacace real-time reverse transcription polymerase chain reaction (RT-PCR) test was performed on patients' nasopharyngeal swabs. RNA was extracted using SaMag

Disclosure. Authors have no conflict of interests, and the work was not supported or funded by any drug company. Dr. Fahda Alokaily is a member of the Editorial Team, and was therefore excluded from any final editorial decisions regarding this paper.
Viral Nucleic Acid Extraction system and the extracted RNA was amplified using BGI- real-time fluorescent RT-PCR kit for the detection of COVID-19.

All symptomatic COVID-19 patients aged 18 years or more who tested positive with laboratory RNA PCR test were included. Any suspected COVID-19 patient without laboratory confirmation was excluded.

The study was approved by the Scientific Research Committee MOHAP/DXB-REC/MMM/ NO.44/2020 and certify that the study was performed in accordance with the ethical standards as laid down in the 1964 Declaration of Helsinki and its later amendments ethical standards.

Data included basic demographics (age, gender), clinical data (symptoms, comorbidities), laboratory parameters (complete blood count, coagulation tests, inflammatory markers, renal function tests, and liver enzymes), admission chest radiography results, in-hospital complications (acute respiratory distress syndrome, acute liver injury, acute kidney injury, acidosis, septic shock, mechanical ventilation, and death). High-sensitivity troponin-I were measured on admission and serially after admission once the cardiac injury was suspected. Data were collected in an excel sheet which was continuously rechecked by 2 researchers. Proper data collection was assured by regular involvement of an epidemiologist.

We categorized patients into 2 groups: those with an acute cardiac injury (ACI) who had at least one documented elevated high-sensitivity troponin-I, and those without cardiac injury who had normal troponin results. The cut-off for the upper limit of normal troponin was taken as $60 \mathrm{ng} / \mathrm{L}$, which is the upper value of the normal range used by our laboratory. We then compared the 2 groups in clinical characteristics and outcomes. Among patients with cardiac injury, we further compared patients with a moderate rise $(\leq 500 \mathrm{ng} / \mathrm{L})$ and a severe rise in troponin $(>500 \mathrm{ng} / \mathrm{L})$ in terms of clinical outcomes (cut-off $500 \mathrm{ng} / \mathrm{L}$ was chosen as an arbitrary number, based on local experience).

The acute cardiac injury was defined as the presence of raised high-sensitivity troponin-I level, with new electrocardiography or echocardiography abnormalities. ${ }^{8}$ Septic shock was defined as the presence of sepsis that is accompanied with persistent hypotension that needs vasopressors to keep mean arterial pressure $\geq 65 \mathrm{~mm} \mathrm{Hg}$ along with high serum lactate level $>2 \mathrm{mmol} / \mathrm{L}(18 \mathrm{mg} / \mathrm{dL})$ despite volume resuscitation. ${ }^{9}$ Acute respiratory distress syndrome was defined according to the Berlin definition that includes the presence of bilateral lung opacities accompanied by respiratory failure not fully explained by cardiac failure 
or fluid overload and low partial pressure of arterial oxygen $\left(\mathrm{PaO}_{2}\right)$ /fraction of inspired oxygen $\left(\mathrm{FiO}_{2}\right)$, within one week of symptom onset. ${ }^{10}$ Acute kidney injury was defined as the presence of either an increase in serum creatinine $\geq 0.3 \mathrm{mg} / \mathrm{dL} \quad(\geq 26.5 \mathrm{umol} / \mathrm{L})$ within 48 hours $/ \geq 1.5$ times baseline, or oliguria with urine output $<0.5 \mathrm{ml} / \mathrm{kg} /$ hour for 6 hours. ${ }^{11}$ Acute liver injury was defined as the presence of raised liver enzymes: alanine aminotransferase (ALT) and/or aspartate aminotransferase (AST) more than 5 times the upper normal limit. The disease severity was classified into mild to moderate (up to mild pneumonia), severe (shortness of breath, high respiratory rate $\geq 30 / \mathrm{min}$, blood oxygen saturation $\leq 93 \%$, the ratio of the $\mathrm{PaO}_{2}$ to a $\mathrm{FiO}_{2}<300$, lung infiltrates $>50 \%$ within $24-48$ hours), and critical (respiratory failure, septic shock, multi-organ dysfunction/failure). ${ }^{12}$

Statisticalanalysis. Categorical variables are expressed as proportions, while continuous data are reported as mean \pm standard deviation. Proportions for categorical variables were compared using the Chi-squared test and Fisher exact test when data were limited. The means for continuous variables were compared using the independent $\mathrm{t}$-tests when the data were normally distributed; otherwise, the Mann-Whitney test was used. Data were analyzed using Statistical Package for Social Sciences version 25.0 (IBM, New York, USA). A p-value of less than 0.05 was considered statistically significant.

Results. Figure 1 shows the flowchart for patient selection. A total of 250 patients were screened who were hospitalized with laboratory-confirmed COVID-19 disease between February 21, 2020, and June 24, 2020. Forty-seven cases were excluded as the troponin test result was not performed at admission. Therefore, 203 cases were included in the final analysis; 44 (21.7\%) with cardiac injury and 159 (78.3\%) without cardiac injury. Overall, the mean age was 48 years (range 13-84 years, SD 14.68), and 151 (74\%) were males. Common symptoms reported were fever $(6.5 \%)$, cough $(55.6 \%)$, and shortness of breath (40.4\%).

Demographics, laboratory results, imaging findings, and in-patient treatment were compared between the 2 groups (Table 1). Compared with patients without cardiac injury, patients with acute cardiac injury were older (mean age 55 years versus 46 years, $p<0.05$ ) and predominantly males $(91 \%$ versus $70.5 \%, p=0.005$. They also presented with higher percentage of shortness of breath $(62 \%$ versus $35 \%, p=0.001)$; had more diabetes $(62 \%$ versus $27 \%, p=0.000)$ and hypertension (55\% versus $32 \%, p=0.004)$. More patients with cardiac injury showed bilateral airspace shadowing on admission chest radiography compared with patients without cardiac injury, (75\% versus $46 \%, p=0.001$ ).

Laboratory tests showed that patients with cardiac injury had lower mean hemoglobin $(p<0.05)$, higher neutrophil count $(p<0.05)$, lower lymphocyte count $(p<0.05)$, higher C-reactive protein $(p<0.05)$, higher procalcitonin $(p<0.05)$, higher ferritin $(p<0.05)$, higher D-dimers $(p<0.05)$, higher lactate dehydrogenase $(p<0.05)$ and lower estimated-glomerular filtration rate $(p<0.05)$. There was no statistical difference in platelet

\section{Laboratory-confirmed Covid-19 patients}

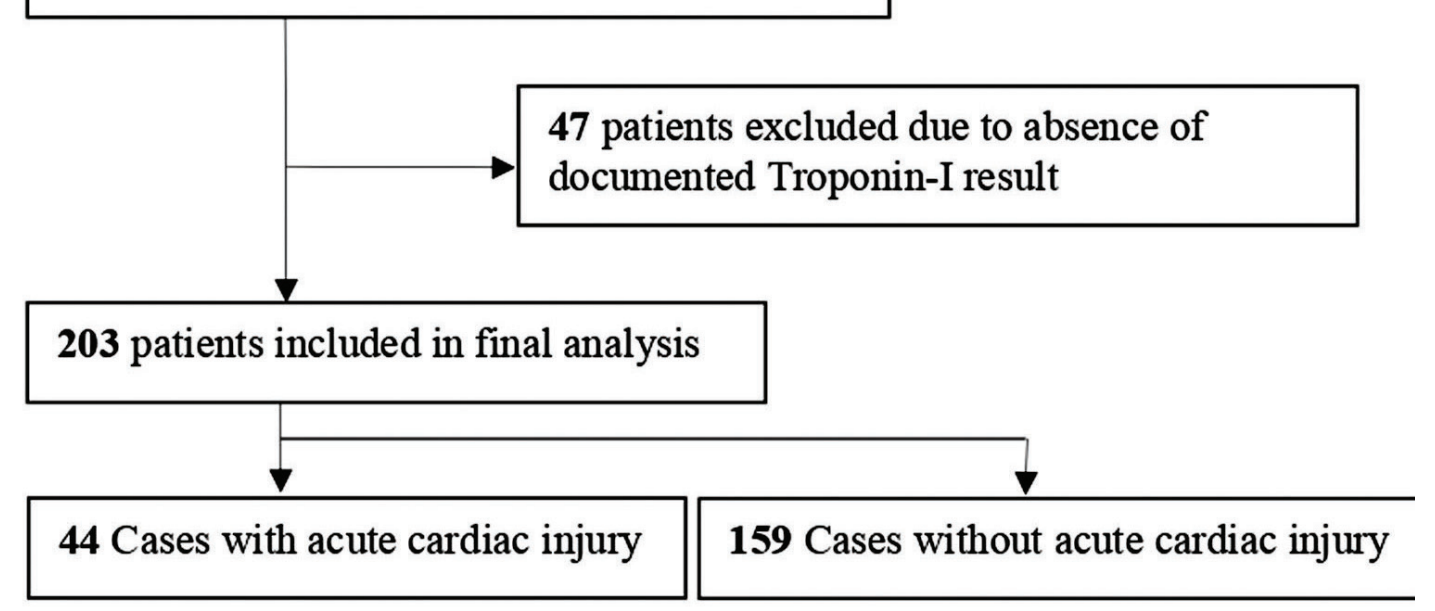

Figure 1 - Flow chart of patient's selection. 
Table 1 - Clinical characteristics (demographics, laboratory, imaging and treatment) of 203 Covid-19 patients; with- and without cardiac injury.

\begin{tabular}{|c|c|c|c|}
\hline \multirow[t]{2}{*}{ Clinical characteristics } & \multicolumn{3}{|c|}{ Acute cardiac injury } \\
\hline & $\begin{array}{c}\text { With } \\
(\mathrm{n}=44)\end{array}$ & $\begin{array}{l}\text { Without } \\
(\mathrm{n}=159)\end{array}$ & $P$-value \\
\hline Age, mean $( \pm S D)$, years & $55 \pm 14$ & $46 \pm 14$ & $<0.05$ \\
\hline Male gender, no. $(\%)$ & $41(91.0)$ & ) $110(70.5)$ & 0.005 \\
\hline \multicolumn{4}{|l|}{ Symptoms, $n(\%)$} \\
\hline Fever & $31(69.0)$ & $103(66.0)$ & 0.719 \\
\hline Cough & $25(55.5)$ & $87(55.7)$ & 0.97 \\
\hline Shortness of breath & $28(62.0)$ & $55(35.0)$ & 0.001 \\
\hline \multicolumn{4}{|l|}{ Co-morbidities, $n$ (\%) } \\
\hline Diabetes & $28(62.0)$ & $42(27.0)$ & 0.000 \\
\hline Hypertension & $25(55.5)$ & $50(32.0)$ & 0.004 \\
\hline Cardiovascular disease & $4 \quad(9.0)$ & $5(3.2)$ & 0.104 \\
\hline \multicolumn{4}{|l|}{ Laboratory findings at admission } \\
\hline Hemoglobin, g/dL, mean $\pm S D$ & $12.6 \pm 1.6$ & $13.3 \pm 1.9$ & $<0.05$ \\
\hline $\begin{array}{l}\text { Neutrophil count, absolute, } \times 10^{3 /} \\
\text { mcL, mean } \pm S D\end{array}$ & $10.5 \pm 5.0$ & $5.6 \pm 3.4$ & $<0.05$ \\
\hline $\begin{array}{l}\text { Neutrophil count }>14 \times 10^{3} / \mathrm{mcL} \\
(\%)\end{array}$ & $19(42.2)$ & $11(7.0)$ & $<0.001$ \\
\hline $\begin{array}{l}\text { Lymphocyte count, absolute, } \\
\mathrm{x} 10^{3} / \mathrm{mcL} \text {, mean } \pm \mathrm{SD}\end{array}$ & $1.0 \pm 0.5$ & $1.5 \pm 0.7$ & $<0.05$ \\
\hline $\begin{array}{l}\text { Lymphocyte count }<1 \times 10^{3} / \mathrm{mcL} \\
(\%)\end{array}$ & $24(53.3)$ & $44(28.2)$ & 0.002 \\
\hline Platelets, $\times 10^{3} / \mathrm{mcL}($ mean $\pm \mathrm{SD})$ & $252 \pm 86.7$ & $245 \pm 93.2$ & 0.560 \\
\hline $\begin{array}{l}\text { Prothrombin time, seconds, } \\
\text { (mean } \pm \text { SD) }\end{array}$ & $13 \pm 1.7$ & $12 \pm 1.7$ & 0.542 \\
\hline $\begin{array}{l}\text { International normalized ratio, } \\
(\text { mean } \pm S D)\end{array}$ & $1.1 \pm 0.1$ & $1.05 \pm 0.1$ & 0.652 \\
\hline $\begin{array}{l}\text { C-reactive protein, } \mathrm{mg} / \mathrm{L} \\
(\mathrm{mean} \pm \mathrm{SD})\end{array}$ & $138.5 \pm 108$ & $59 \pm 75$ & $<0.05$ \\
\hline C-reactive protein $>3 \mathrm{mg} / \mathrm{L}(\%)$ & $43(95.5)$ & $128(82.0)$ & 0.08 \\
\hline Procalcitonin, ug/L (mean $\pm S D)$ & $3.4 \pm 8.9$ & $0.3 \pm 1.2$ & $<0.05$ \\
\hline Procalcitonin $>0.1 \mathrm{ug} / \mathrm{L}(\%)$ & $35(77.8)$ & $41(26.3)$ & 0.000 \\
\hline Ferritin, mcg/L $($ mean $\pm S D)$ & $1963 \pm 2840$ & $870 \pm 1229$ & $<0.05$ \\
\hline Ferritin >388 mcg/L (\%) & $37(82.2)$ & $69(44.2)$ & 0.000 \\
\hline D-dimers, mg/dL $($ mean $\pm S D)$ & $6.4 \pm 9.8$ & $1.7 \pm 4.1$ & $<0.05$ \\
\hline D-dimers $>0.5$ mg/dL (\%) & $34(75.5)$ & $75(48.0)$ & 0.001 \\
\hline $\begin{array}{l}\text { Lactate dehydrogenase, IU/L } \\
(\text { mean } \pm \text { SD) }\end{array}$ & $614 \pm 686$ & $314 \pm 197$ & $<0.05$ \\
\hline $\begin{array}{l}\text { Lactate dehydrogenase }>227 \\
\text { IU/L }(\%)\end{array}$ & $39(86.0)$ & $101(64.0)$ & 0.017 \\
\hline Creatinine, umol/L $(\operatorname{mean} \pm S D)$ & $184 \pm 342$ & $93 \pm 73$ & $<0.05$ \\
\hline $\mathrm{e}-\mathrm{GFR}, \mathrm{ml} / \mathrm{min}(\operatorname{mean} \pm \mathrm{SD})$ & $66.5 \pm 31$ & $94 \pm 27$ & $<0.05$ \\
\hline
\end{tabular}

Table 1 - Clinical characteristics (demographics, laboratory, imaging and treatment) of 203 Covid-19 patients; with- and without cardiac injury (continued).

\begin{tabular}{lccc}
\hline Clinical characteristics & \multicolumn{3}{c}{ Acute cardiac injury } \\
& $\begin{array}{c}\text { With } \\
(\mathbf{n}=44)\end{array}$ & $\begin{array}{c}\text { Without } \\
(\mathbf{n}=159)\end{array}$ & $P$-value \\
\hline $\begin{array}{l}\text { Alanine aminotransferase, IU/L } \\
\text { (mean } \pm \text { SD) }\end{array}$ & $49 \pm 28.3$ & $72 \pm 174$ & NS \\
$\begin{array}{l}\text { Aspartate aminotransferase, IU/L } \\
\text { (mean } \pm \text { SD) }\end{array}$ & $60 \pm 47$ & $50 \pm 75$ & NS \\
Albumin, gm/l (mean \pm SD) & $25.7 \pm 6.5$ & $32 \pm 6.5$ & $<0.05$ \\
Chest radiography at admission $n(\%)$ & & & \\
Bilateral opacities & $34(75.5)$ & $72(46.0)$ & 0.001 \\
Treatment, $n$ (\%) & & & \\
Chloroquine/hydroxychloroquine & $43(97.0)$ & $150(96.0)$ & 0.155 \\
Lopinavir-ritonavir & $41(91.0)$ & $128(82.0)$ & 0.14 \\
Favipiravir & $12(27.0)$ & $28(18.0)$ & 0.19 \\
Intravenous antibiotics & $41(91.0)$ & $88(56.4)$ & $<0.001$ \\
Intravenous steroids & $34(75.5)$ & $56(35.9)$ & $<0.001$ \\
Interferon & $2(4.0)$ & $12(7.7)$ & 0.45 \\
Tocilizumab & $21(46.7)$ & $19(12.0)$ & $<0.001$ \\
Antifungals & $10(22.0)$ & $7(4.5)$ & $<0.001$ \\
\hline
\end{tabular}

eGFR: estimated glomerular filtration rate.

Data is expressed as mean ( \pm standard deviation) for continuous variables and counts (percentages) for categorical variables. P value less than 0.05 is considered statistically significant

counts, coagulation parameters, and liver enzymes between the 2 groups.

The severity of disease and in-hospital complications were also compared between the 2 groups (Table 2). More patients with cardiac injury had a critical disease, while more patients without cardiac injury had mild to moderate disease $(84.4 \%$ versus $18 \%, p=0.00)$. Regarding the outcomes and complications, patients with cardiac injury had higher intensive care admissions $(82 \%$ versus $18.5 \%, p=0.00)$ and complications including acute kidney injury $(75 \%$ versus $9.6 \%$, $p=0.00)$, acidosis $(75.5 \%$ versus $8.3 \%, p=0.00)$, septic shock $(66.7 \%$ versus $2.6 \%, p=0.00)$, acute respiratory distress syndrome $(84 \%$ versus $17 \%, p=0.00)$. As well, despite there were no difference in LFTs between the 2 groups was found in the laboratory carried out on admission, whereas, we diagnosed acute liver injury in patients who developed a rise of ALT/AST $>5$ times the upper normal limit during the course of in-hospital 
Table 2 - Comparison of clinical outcomes of 203 Covid-19 patients; with- and without cardiac injury.

\begin{tabular}{|c|c|c|c|}
\hline \multirow[t]{2}{*}{ Characteristic } & \multicolumn{3}{|c|}{ Acute cardiac injury } \\
\hline & $\begin{array}{l}\text { With } \\
\mathrm{n}=44\end{array}$ & $\begin{array}{c}\text { Without } \\
\mathrm{n}=159\end{array}$ & $P$-value \\
\hline \multicolumn{4}{|l|}{ Severity of disease } \\
\hline Mild to moderate & $4 \quad(9.0)$ & $74(48.0)$ & \\
\hline Severe & $3(6.7)$ & $53(34.2)$ & $<0.001$ \\
\hline Critical & $38(84.4)$ & $28(18.0)$ & \\
\hline \multicolumn{4}{|l|}{ Outcomes } \\
\hline Admission to intensive care unit & $36(82.0)$ & $29(18.5)$ & $<0.001$ \\
\hline $\begin{array}{l}\text { Acute respiratory distress } \\
\text { syndrome }\end{array}$ & $38(84.4)$ & $26(16.7)$ & $<0.001$ \\
\hline Acute kidney injury & $33(75.0)$ & $15(9.6)$ & $<0.001$ \\
\hline Acute liver injury & $13(29.0)$ & $16(10.2)$ & 0.002 \\
\hline Acidosis & $34(75.5)$ & $13(8.3)$ & $<0.001$ \\
\hline Septic shock & $30(66.7)$ & $4(2.6)$ & $<0.001$ \\
\hline Mechanical ventilation & $32(71.0)$ & $9 \quad(5.8)$ & $<0.001$ \\
\hline Death & $31(68.9)$ & $8 \quad(5.1)$ & $<0.001$ \\
\hline
\end{tabular}

stay. Therefore, although there was no difference in liver enzymes upon admission, the patient with cardiac injury developed more acute liver injury than the other during the hospital stay with acute liver injury (29\% versus $10 \%, p=0.002)$. Patients with cardiac injury needed more mechanical ventilation $(71 \%$ versus $6 \%$, $p=0.00)$ and had a significantly higher risk of death (69\% versus $5 \%, p=0.00$ ).

We also compared the outcomes in patients with moderate rise in peak troponin level $(\leq 500 \mathrm{ng} / \mathrm{L})$ and those with high peak troponin levels ( $>500 \mathrm{ng} / \mathrm{L}$ ) (Table 3). There was no statistical difference between the 2 groups regarding admission to the intensive care $(p=0.550)$, acute respiratory distress syndrome $(p=0.826)$, acute kidney injury $(p=0.787)$, acute liver injury $(p=0.173)$, acidosis $(p=0.430)$, septic shock $(p=0.204)$, mechanical ventilation $(p=0.964)$ and death $(p=0.787)$.

Discussion. This study aimed to provide an insight into the association between acute cardiac injury and clinical outcomes, including death in laboratory-confirmed Covid-19 patients. We compared clinical characteristics between patients with acute cardiac injury and those without cardiac injury. Acute cardiac injury (ACI) was present in more than fifth
Table 3 - Comparison of outcomes in patients with acute cardiac injury according to the level of troponin rise $(\mathrm{N}=44)$.

\begin{tabular}{lccc}
\hline Outcomes & \multicolumn{3}{c}{ Peak high-sensitivity troponin I value } \\
& $\begin{array}{c}\leq 500 \mathbf{n g} / \mathrm{L} \\
(\mathbf{n}=20)\end{array}$ & $\begin{array}{c}>500 \mathbf{n g} / \mathrm{L} \\
(\mathbf{n}=\mathbf{2 4})\end{array}$ & $P$-value \\
\hline $\begin{array}{l}\text { Admission to intensive care unit } \\
\text { Acute respiratory distress }\end{array}$ & $16(80)$ & $20(83.0)$ & 0.550 \\
syndrome & $18(90)$ & $20(83.0)$ & 0.826 \\
Acute kidney injury & $15(75)$ & $18(75.0)$ & 0.787 \\
Acute liver injury & $4(20)$ & $9(37.5)$ & 0.173 \\
Acidosis & $17(85)$ & $17(71.0)$ & 0.430 \\
Septic shock & $12(60)$ & $18(75.0)$ & 0.204 \\
Mechanical ventilation & $15(75)$ & $17(71.0)$ & 0.964 \\
Death & $15(75)$ & $18(75.0)$ & 0.787 \\
\hline \multicolumn{4}{c}{ Values are expressed as number and percentage (\%) } \\
\hline \multicolumn{4}{c}{} \\
\hline
\end{tabular}

of COVID-19 patients. We found that the majority were male and older in age and had worse clinical presentation, comorbidities, laboratory parameters, and clinical outcomes.

We report an incidence of acute cardiac injury to be $21.7 \%$ (44/203). This is high compared to what Huang et $\mathrm{al}^{3}$ reported (12\%). Also, a study of 138 Covid-19 patients admitted to the hospital reports an incidence of $7.2 \%$ for acute myocardial injury while $16.7 \%$ had arrhythmias. ${ }^{3}$ Our high reported incidence is likely related to the high prevalence of diabetes and hypertension in the region. We noted in our study that more patients in the cardiac injury group were diabetics and hypertensives, rendering them prone to cardiac injury.

Several laboratory parameters have been identified to predict adverse outcomes in COVID-19 patients. Wu et $\mathrm{al}^{13}$ detected the presence of low lymphocytes, high C-reactive protein, ferritin, and lactate dehydrogenase in these patients and further found these to be associated with the development of acute respiratory distress syndrome, need for intensive care, and even high mortality. In the present study, patients with acute cardiac injury have a high prevalence of hematologic abnormalities like neutrophilia and lymphopenia. These patients were also found to have higher inflammatory markers like C-reactive protein, procalcitonin, ferritin, D-dimers, and lactate dehydrogenase compared to the non-cardiac injury group. This suggests the association of severe inflammation to the risk of developing cardiac injury and the need for close monitoring of these patients. We also found that patients who develop 
critical disease were more likely to develop acute cardiac injury. High troponin levels have been reported to be associated with adverse clinical outcomes. A study of 191 COVID-19 patients revealed the odds ratio for death when high-sensitivity Troponin-I concentrations were high to be 80.1 ( $95 \%$ confidence interval 10.3 to $620.4, p<0.0001) .{ }^{14}$ Similarly, another study of 416 Covid-19 reported that patients who developed high cardiac troponin levels were more at risk to develop acute respiratory distress syndrome or acute kidney injury, require invasive or non-invasive ventilation, and a 10 -fold increase in mortality. ${ }^{15}$ In concordance to the existing literature, we also found a significant association in our study between acute cardiac injury and several adverse outcome measures. Our patients with acute cardiac injury developed more multi-organ dysfunction, required intensive care and mechanical ventilation with high mortality. No cut-off for the level of troponin rise has been reported in the literature for the development of adverse outcomes. We compared patients with a moderate rise in troponin $(\leq 500 \mathrm{ng} / \mathrm{L})$ to severe rise $(>500 \mathrm{ng} / \mathrm{L})$ and found that the risk of having adverse outcomes was similar. This highlights the fact that even low degrees of troponin leak is associated with serious outcomes and need to be monitored closely. Only few case reports suggest the successful treatment of Covid-19 related to myocarditis (high troponin levels) with methylprednisolone, immunoglobulin, inotropes, and ventilatory support. ${ }^{16,17}$ The European Society of Cardiology position statement ${ }^{18}$ recommends treating patients with acute myocarditis and cardiogenic shock with inotropes/vasopressors and mechanical ventilation. Additionally, extracorporeal membrane oxygenation (ECMO) and ventricular assist devices are recommended for patients that require longer-term support.

Study limitations. Firstly, this is a single center study with analysis of a small cohort of patients. Secondly, the data does not include information on echocardiography, electrocardiography (ECG), and cytokine level measurements, hence the inability to determine the potential mechanisms of cardiac injury. We understand that such data needs to be cautiously interpreted and provides a basic understanding of high-risk patient cohort.

This study represents rare data from the Middle East region. It adds to the existing scientific knowledge in this aspect from other parts of the world and explores the association of acute cardiac injury with clinical outcomes in a diverse population in UAE. The study highlights implications for future research in the management of these patients in the form of aggressive cardiovascular support and tertiary center care.

In conclusion, acute cardiac injury is common in patients hospitalized for laboratory-confirmed COVID-19 disease in the Middle East with high prevalence of non-communicable diseases such as obesity, diabetes, and hypertension. These patients present with worse clinical presentations and laboratory abnormalities including high neutrophils, low lymphocytes, high inflammatory markers, and bilateral air space opacification on chest radiography. The risk of in-hospital multi-organ damage, need for mechanical ventilation, and death is significantly higher in patients with an acute cardiac injury. This high risk appears to be the same in patients with a moderate or high rise in peak troponin levels. Hence, early recognition with prompt management would be the best clinical practice approach with multidisciplinary team involvement.

\section{References}

1. Zhu N, Zhang D, Wang W, Li X, Yang B, Song J, et al. A Novel coronavirus from patients with pneumonia in China, 2019. N Engl J Med 2020; 382: 727-733.

2. Johns Hopkins Coronavirus Resource Center. Center for Systems Science and Engineering (CSSE) at Johns Hopkins University U. [cited 2020]. Available from: https://coronavirus.jhu.edu/map.html

3. Huang C, Wang Y, Li X, Ren L, Zhao J, Hu Y, et al. Clinical features of patients infected with 2019 novel coronavirus in Wuhan, China. Lancet 2020; 395: 497-506.

4. Wang D, Hu B, Hu C, Zhu F, Liu X, Zhang J, et al. Clinical Characteristics of 138 hospitalized patients with 2019 novel coronavirus-infected pneumonia in Wuhan, China. JAMA 2020; 323: 1061-1069.

5. Shi S, Qin M, Shen B, Cai Y, Liu T, Yang F, et al. Association of Cardiac Injury With Mortality in Hospitalized Patients With COVID-19 in Wuhan, China. JAMA Cardiology 2020: e200950.

6. Chen C, Zhou Y, Wang DW. SARS-CoV-2: a potential novel etiology of fulminant myocarditis. Herz 2020; 45: 230-232.

7. Zheng YY, Ma YT, Zhang JY, Xie X. COVID-19 and the cardiovascular system. Nat Rev Cardiol 2020; 17: 259-260.

8. B K A, Chaudhuri D. A review of acute myocardial injury in coronavirus disease 2019. Cureus 2020; 12: e8426.

9. Singer M, Deutschman CS, Seymour CW, Shankar-Hari M, Annane D, Bauer M, et al. The Third International Consensus definitions for sepsis and septic shock (Sepsis-3). JAMA 2016; 315: 801-810.

10. Force TADT. Acute Respiratory Distress Syndrome: The Berlin Definition. JAMA 2012; 307: 2526-2533.

11. Khwaja A. KDIGO Clinical Practice Guidelines for Acute Kidney Injury. Nephron Clinical Practice 2012; 120: c179-c184.

12. Epidemiology Working Group for NCIP Epidemic Response, Chinese Center for Disease Control and Prevention. The epidemiological characteristics of an outbreak of 2019 novel coronavirus diseases (COVID-19) in China. Zhonghua Liu Xing Bing Xue Za Zhi 2020; 41: 145-151. Chinese. 
13. Wu C, Chen X, Cai Y, Xia Ja, Zhou X, Xu S, et al. Risk factors associated with acute respiratory distress syndrome and death in patients with coronavirus disease 2019 pneumonia in Wuhan, China. JAMA Internal Medicine 2020; 180: 934-943.

14. Zhou F, Yu T, Du R, Fan G, Liu Y, Liu Z, et al. Clinical course and risk factors for mortality of adult inpatients with COVID-19 in Wuhan, China: a retrospective cohort study. The Lancet 2020; 395: 1054-1062.

15. Shi S, Qin M, Shen B, Cai Y, Liu T, Yang F, et al. Association of Cardiac Injury With Mortality in Hospitalized Patients With COVID-19 in Wuhan, China. JAMA Cardiology 2020; 5: 802-810.
16. Zeng JH, Liu YX, Yuan J, Wang FX, Wu WB, Li JX, et al. First case of COVID-19 complicated with fulminant myocarditis: a case report and insights. Infection 2020; 48: 773-777.

17. $\mathrm{Hu} \mathrm{H}, \mathrm{Ma} \mathrm{F}$, Wei X, Fang Y. Coronavirus fulminant myocarditis treated with glucocorticoid and human immunoglobulin. European Heart Journal 2020; 16: ehaa190.

18. Caforio ALP, Pankuweit S, Arbustini E, Basso C, GimenoBlanes J, Felix SB, et al. Current state of knowledge on aetiology, diagnosis, management, and therapy of myocarditis: a position statement of the European Society of Cardiology Working Group on Myocardial and Pericardial Diseases. European Heart Journal 2013; 34: 2636-2648. 